\title{
중공형 전면추를 가진 Tonpilz 트랜스듀서 연구 Study on the Wideband Tonpilz Transducer with a Cavity-Type Head Mass
}

\author{
김현기, 임영섭*, 노용래 ${ }^{\dagger}$ \\ (Hyunki Kim, Youngsub Lim*, and Yongrae Roh ${ }^{\dagger}$ ) \\ 경북대학교 기계공학과, *경북대학교 센서 및 디스플레이공학과 \\ (접수일자: 2014년 1월 21일; 채택일자: 2014년 3월 6일)
}

\begin{abstract}
초 록: 본 연구에서는 수중 음향 트랜스듀서의 주파수 광대역화를 위해서 중공형 전면추를 가진 Tonpilz 트랜스듀서 를 제안하였다. 트랜스듀서의 특성에 미치는 설계변수들의 영향을 분석하고, 그 결과에 따라 Tonpilz 트랜스듀서의 최적구조를 설계하였다. 나아가 시편의 제작 및 특성 측정을 통하여 설계 결과의 타당성을 검증하였다. 설계된 트랜스 듀서는 단일모드 트랜스듀서에 비해 월등히 넓은 $131 \%$ 의 $-6 \mathrm{~dB}$ 비대역폭을 나타내었으며, 해석 결과와측정 결과가 잘 일치하는 것으로 확인되었다.

핵심용어: Tonpilz 트랜스듀서, 중공형, 광대역, 송신음압감도(TVR)
\end{abstract}

\begin{abstract}
In this work, we present an underwater acoustic transducer with a cavity-type head mass to achieve a wide frequency bandwidth. We analyzed the effects of design variables on the transducer characteristics, and optimized the structure of the Tonpilz transducer based on the analysis results. Further, validity of the design was verified by manufacturing a prototype of the transducer and measuring its properties. The designed transducer had a far wider $-6 \mathrm{~dB}$ fractional bandwidth which is $131 \%$ than that of a single mode transducer, and the measured results were confirmed to be in good agreement with the analysis results.
\end{abstract}

Keywords: Tonpilz transducer, Cavity, Wideband, Transmitting Voltage Response (TVR)

PACS numbers: 43.30. Yj, 43.38. Fx

\section{I. 서 론}

수중 탐지 및 통신용으로 사용되는 대표적인 음향 트랜스듀서인 Tonpilz 트랜스듀서는 음향파를 방사 하기 위한 방사체 역할의 전면추, 구동소자, 전면추 의 변위를 증폭시키는 후면추 그리고 구성요소를 고 정하는 볼트로 구성된다. 일반적인 Tonpilz 트랜스듀 서는 비교적 단순한 구조로 고출력 송신이 가능한 장점 때문에 많이 사용되고 있지만, 종방향 공진 모 드만 이용하기 때문에 주파수 대역폭이 넓지 않다. ${ }^{[1]}$ 하지만수중트랜스듀서의 주응용 분야가 단일 목표 탐지에서 다중 목표의 식별로 옮겨감에 따라 향상된

†Corresponding author: Yongrae Roh (yryong@knu.ac.kr) School of Mechanical Engineering, Kyungpook National University, 1370 Sankyukdong, Bukgu, Daegu 702-701, Republic of Korea (Tel: 82-53-950-6828, Fax: 82-53-943-8716)
거리 분해능을 가지기 위해서 광대역 트랜스듀서가 필요하게 되었고, ${ }^{[2]}$ 주파수 대역폭을 넓히기 위해서 하나의 모드만을 이용하는 것이 아니라 2 개 이상의 다른 모드들을 결합하는 다중모드 트랜스듀서에 대 한 연구가 활발히 이루어졌다. 공진주파수가 다른 두 가지의 구동소자를 하나의 트랜스듀서에 적용하 여 두 개의 종방향 모드를 결합함으로써 대역폭을 넓히는 방안과 구동소자에 2 개 이상의 다른 구동 신 호를 인가하여 대역폭을 넓히는 방안이 연구되었 다. ${ }^{[-5]}$ 또한 하나의 Tonpilz 트랜스듀서에 2개 이상의 전면추를 장착하여 부가적인 공진모드를 발생시켜 대역폭을 넓히는 방안도 제안되었다. ${ }^{[6,7]}$ 그 외에도 구동자의 종방향 모드와 전면추의 가장자리 부분이 휘는 flapping 모드를 결합하는 방안 등 대역폭을 넓 
히기 위한 다양한 방법들이 연구되었다. ${ }^{[8,9]}$

이상에서 제시된 다양한 연구 중에서 Tonpilz 트랜 스듀서의 장점인 단순한 구조를 유지하면서 주파수 대역폭을 넓히는 방법으로 종방향 모드와 flapping 모드의 결합을 이용하는 방법이 가장 효과적이라 할 수 있다. 종방향 모드와 flapping 모드를 결합할 때에 는, 두 모드의 구동주파수 차이가 크고 트랜스듀서 의 품질계수 $\mathrm{Q}$ 가 작을수록 유리하다. 종방향 모드의 주파수는 구동소자에 의해서 정해지므로 대역폭을 조절하기 위해서는 flapping 모드 주파수를 변화시켜 야하는데, flapping 모드는 전면추의 두께에 의해 많 은 영향을 받는다. ${ }^{[8,10]}$ 하지만 두 모드의 주파수차이 를 증가시키기 위해 전면추를 두껍게 하면 전면추의 질량이 증가되어 품질계수가 증가하게 된다. 종방향 모드와 flapping 모드의 주파수 차이가 크더라도 높 은 품질계수를 가지면 두 모드의 결합이 적절히 이 루어질 수 없다. 이러한 문제를 해결하기 위한 방법 으로 Tonpilz 트랜스듀서의 전면추에 빈 공간을 만들 어서 품질계수를 감소시키는 방법이 연구되었다. ${ }^{10]}$ 이는 flapping 모드의 구동주파수를 높이기 위해서 전면추의 두께를 크게 증가시켜도 전면추 내에 빈 공간이 있으므로 질량이 크게 증가하지 않아 낮은 품질계수를 유지할 수 있으므로 광대역 특성의 구현 이 용이해진다는 장점이 있다. 하지만 기 발표된 연 구에서 중공형 Tonpilz 트랜스듀서의 개념을 소개하 였고 그 성능은 수치해석 결과만으로 평가하여, 해 석 결과의 타당성을 실험적으로 검증할 필요가 있 다. 따라서 본 논문에서는 전면추에 빈 공간을 적용 한 중공형 Tonpilz 트랜스듀서의 최적구조를 설계하 고, 설계결과에 따라 시험편을 제작한 후 그 성능을 측정하여 설계 결과의 타당성을 검증하고자 하였다.

\section{2. 트랜스듀서의 특성 해석}

본 연구에서는 유한요소 해석을 통하여 설계변수 의 변화에 따른 트랜스듀서 특성의 변화를 해석하였 다. 해석은 상용 유한요소 해석 프로그램인 ANSYS 를 이용하였으며, Tonpilz 트랜스듀서의 2차원 축대 칭 모델은 Fig. 1과 같다. 전면추는 중공형태를 가지 며, 구동소자는 12 층의 압전복합체로 구성되어있다.
실제측정 상황을 고려하여 물과 트랜스듀서 전면추 사이에 음향창을 설치하였다. 공기 중에서의 음향특 성을 측정하기 위한 모델은 약 19,000 개의 절점과 20,000 개의 요소로 구성되었으며, 수중 모델은 약 35,000 개의 절점과 36,000 개의 요소로 구성되었다. 수중 모델에서 물의 반경은 충분히 넓게 하여 원거 리 음장이 묘사될 수 있도록 하였으며, 물의 최외곽 에는 무반사 경계조건을 설정하였다. 트랜스듀서를 구성하는 재료와 물성은 Table 1에 나타내었다. 구동 소자로는 단일 세라믹보다 광대역특성을 가지는 1-3형 압전복합체를 사용하였는데, 복합체를 구성 하는 압전세라믹으로는 PZT-5H, 폴리머로는 Dow corning (Midland, MI)사의 점도가 낮은 에폭시를 사 용하였으며, 세라믹의 부피비는 $50 \%$ 이다. ${ }^{[11]}$ 전면추와 후면추의 재료는 알루미늄과 황동으로 선정하였다.

최적화를 위한 설계변수로는 Tonpilz 트랜스듀서 의 구조에서 주파수 특성에 가장 많은 영향을 미치 는 전면추 전체의 두께, 전면추 상판의 두께, 후면추 의 두께로 정하였으며, 각 변수들의 변화 범위는 제 작이 용이한 크기로 Table 2와같이 설정하였다. 중심

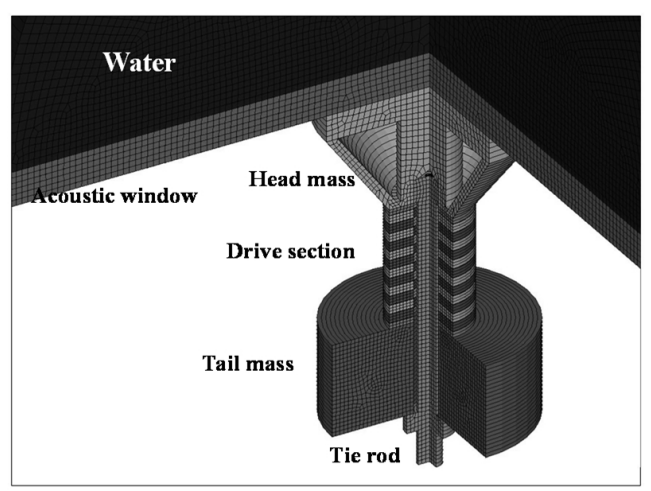

Fig. 1. Finite element model of the Tonpilz transducer.

Table 1. Material properties of the transducer's components.

\begin{tabular}{c|c|c|c}
\hline \hline $\begin{array}{c}\text { Transducer } \\
\text { component }\end{array}$ & $\begin{array}{c}\text { Young's } \\
\text { modulus [GPa] }\end{array}$ & Poisson's ratio & $\begin{array}{c}\text { Density } \\
{\left[\mathrm{kg} / \mathrm{m}^{3}\right]}\end{array}$ \\
\hline Head mass & 68.9 & 0.33 & 2,700 \\
\hline Tail mass & 104.0 & 0.33 & 8,800 \\
\hline Tie rod & 128 & 0.30 & 8,250 \\
\hline $\begin{array}{c}\text { Acoustic } \\
\text { window }\end{array}$ & 0.2 & 0.48 & 1,060 \\
\hline Drive section & \multicolumn{3}{|c}{$1-3$ piezoelectric composite } \\
\hline
\end{tabular}


Table 2. Variation range of the structural variables.

\begin{tabular}{c|c|c|c}
\hline \hline $\begin{array}{c}\text { Normalization } \\
\text { factor }\end{array}$ & $\begin{array}{c}\text { Head mass } \\
\text { thickness (mm) }\end{array}$ & $\begin{array}{c}\text { Upper plate } \\
\text { thickness (mm) }\end{array}$ & $\begin{array}{c}\text { Tail mass } \\
\text { thickness }(\mathrm{mm})\end{array}$ \\
\hline-1.0 & 15.6 & 3.5 & 14.0 \\
\hline-0.5 & 17.6 & 4.0 & 15.0 \\
\hline 0.0 (basic) & 19.6 & 4.5 & 16.0 \\
\hline 0.5 & 21.6 & 5.0 & 17.0 \\
\hline 1.0 & 23.6 & 5.5 & 18.0 \\
\hline
\end{tabular}

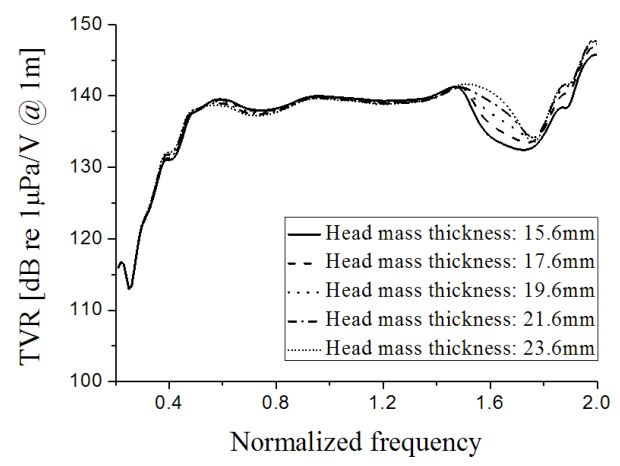

Fig. 2. TVR spectra in accordance with the variation of the head mass thickness.

합성계획에 따라 설계변수의 최소값과 최대값을 -1.0 과 1.0 으로, 기본 모델의 수치를 0 으로 정규화하 였다. ${ }^{[12]}$ 트랜스듀서 특성 변화를 효과적으로 분석하 기 위해 정규화된 수치 \pm 0.5 에 대해서도 중심합성계 획을 이용하여 분석대상 경우들을 선정하였으며, 총 29 개의 경우들을 분석하였다.

유한요소 해석을 통해 설정된 범위 내에서의 트랜 스듀서의 Transmitting Voltage Response(TVR) 스펙트 럼을 구하였으며, 도출된 TVR 스펙트럼은 Table 2에 표시한 기본 모델의 중심주파수에 대해 정규화하여 나타내었다.

첫 번째 설계 변수인 전면추 두께의 변화에 따른 TVR 스펙트럼의 변화는 Fig. 2 와 같으며, 여기서 -6 $\mathrm{dB}$ 대역폭과 중심주파수 및 주파수 대역폭내 하한 주파수의 변화경향을 추출하여 Fig. 3에 별도로 나타 내었다. 그림에서 $\triangle f$ 는 $-6 \mathrm{~dB}$ 대역폭, $f_{c}$ 는 중심주파 수, $f_{1}$ 은 대역폭내 하한주파수를 각각 나타낸다. 변 화경향을 살펴보면 전면추의 두께가 $21.6 \mathrm{~mm}$ 일 때 대역폭이 최대가 되는 것을 확인할 수 있으며, 전면 추 두께의 변화에도 하한주파수의 변화가 미미하여 중심주파수의 변화경향이 대역폭의 변화경향을 따

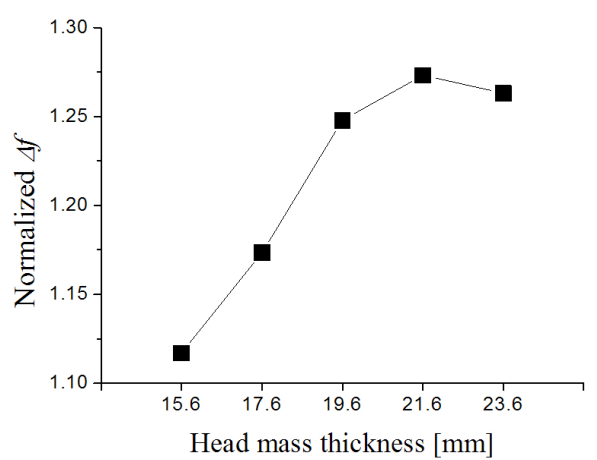

(a)

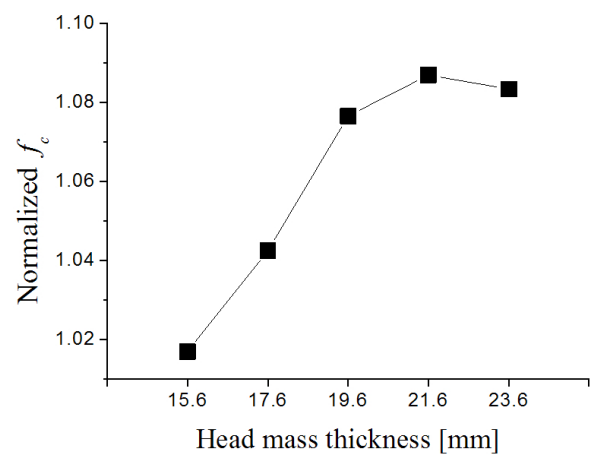

(b)

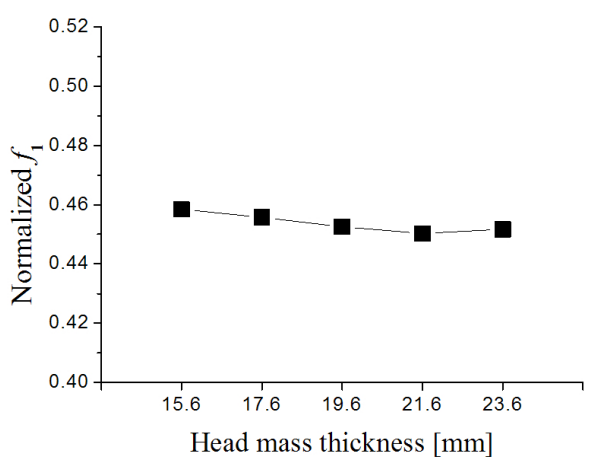

(c)

Fig. 3. Variation of Tonpilz properties in accordance with the variation of the head mass thickness: (a) $\Delta \mathrm{f}$, (b) $f_{c}$, (c) $f_{1}$.

라가는 것을 알 수 있다.

다음은 두 번째 설계 변수인 전면추 상판의 두께 를 $3.5 \mathrm{~mm}$ 에서 $5.5 \mathrm{~mm}$ 까지 $0.5 \mathrm{~mm}$ 간격으로 변화시 켜가며 TVR 변화경향을 파악하였다. TVR 스펙트럼 의 변화는 Fig. 4에, 대역폭과 중심주파수, 하한주파 수의 변화경향은 Fig. 5 에 각각 나타내었다. 전면추 상판의 두께가 $4.5 \mathrm{~mm}$ 에서 대역폭이 최대가 되는 것 을 확인할 수 있으며, 전면추 상판의 두께가 두꺼워 질수록 하한주파수가 낮아지는 경향과 대역폭의 경 


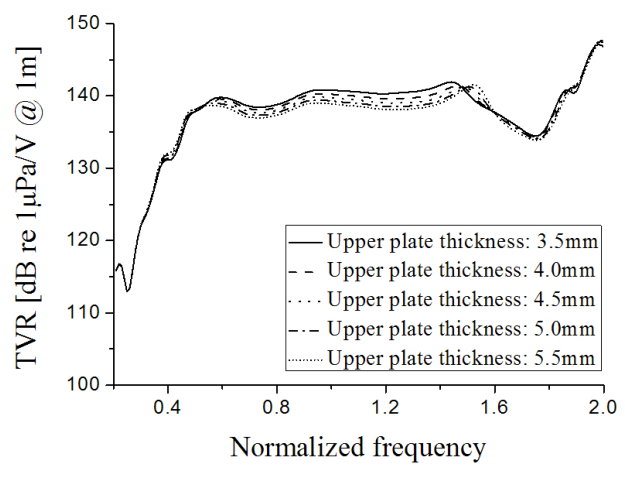

Fig. 4. TVR spectra in accordance with the variation of the upper plate thickness.

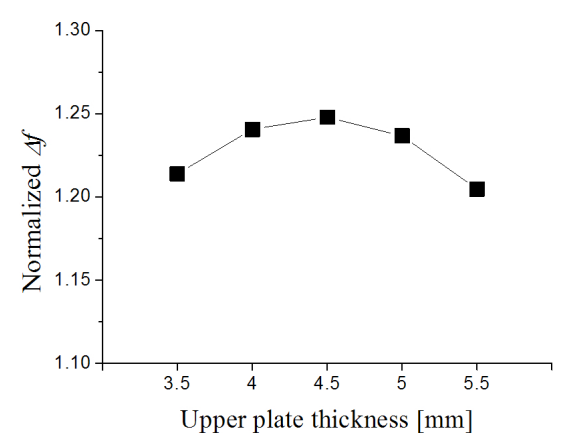

(a)

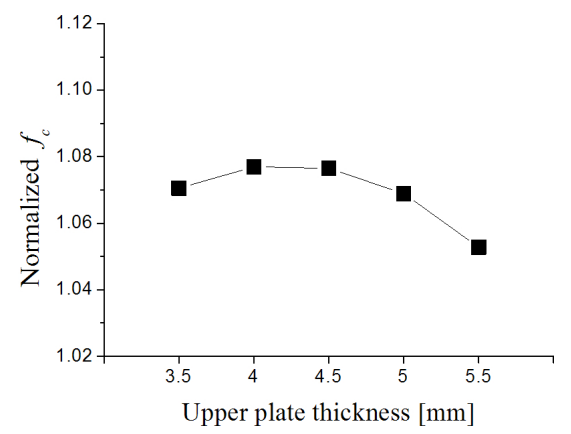

(b)

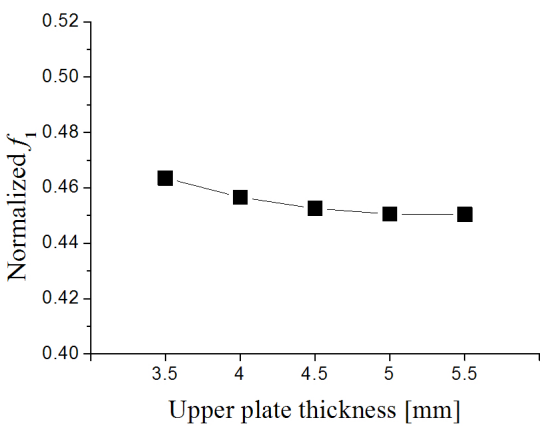

(c)

Fig. 5. Variation of Tonpilz properties in accordance with the variation of the upper plate thickness: (a) $\Delta \mathrm{f}$, (b) $f_{c}$, (c) $f_{1}$.

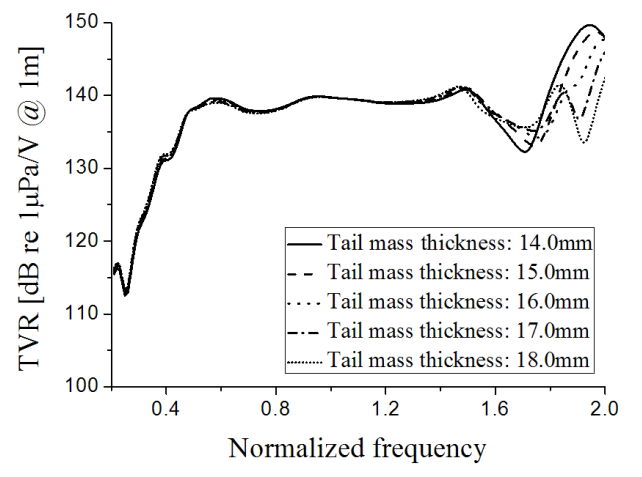

Fig. 6. TVR spectra in accordance with the variation of the tail mass thickness.

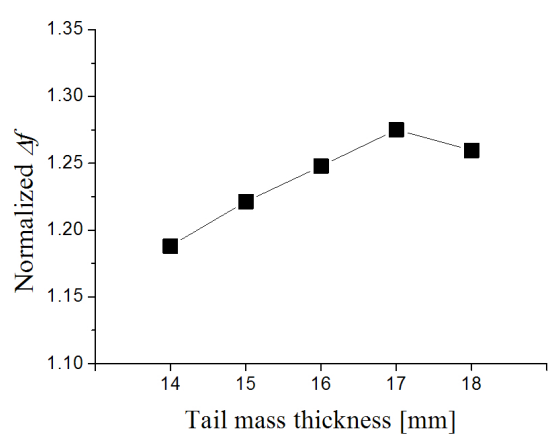

(a)

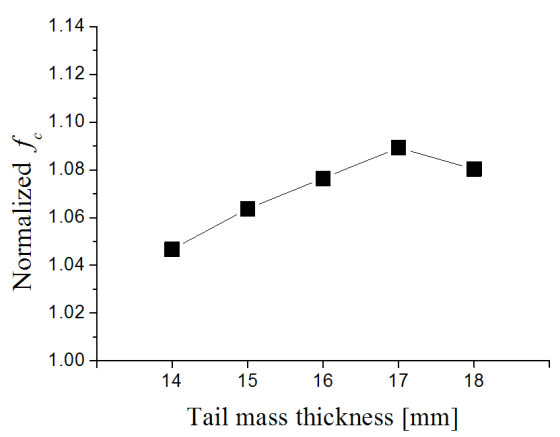

(b)

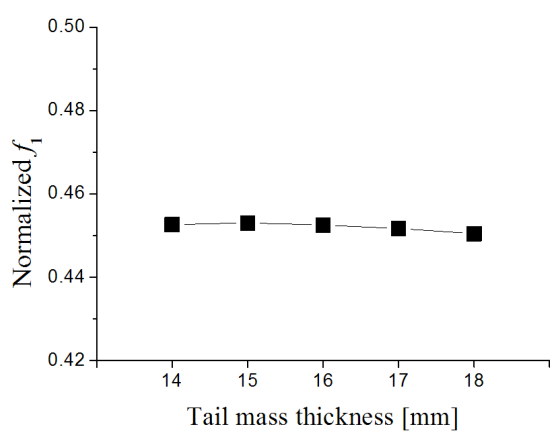

(c)

Fig. 7. Variation of Tonpilz properties in accordance with the variation of the tail mass thickness: (a) $\Delta f$, (b) $f_{c}$, (c) $f_{1}$. 
향이 중심주파수의 경향에 복합적으로 나타나는 것 을 볼 수 있다.

마지막으로 세 번째 설계 변수인 후면추의 두께를 $14.0 \mathrm{~mm}$ 에서 $18.0 \mathrm{~mm}$ 까지 $1.0 \mathrm{~mm}$ 간격으로 변화시켜 가며 TVR 스펙트럼의 변화를 Fig. 6, 대역폭과 중심 주파수, 그리고 하한주파수의 변화경향을 Fig. 7과 같이 분석하였다. 후면추의 두께 $17 \mathrm{~mm}$ 에서 대역폭 이 최대가 되는 것을 확인할 수 있으며, 전면추 두께 와 마찬가지로 후면추 두께가 변하여도 하한주파수 의 변화가 미미하여 중심주파수의 변화경향이 대역 폭의 변화경향을 따라가는 것을 볼 수 있다.

\section{3. 트랜스듀서의 최적구조 설계}

2절에서 전면추의 두께, 전면추 상판의 두께, 후면 추의 두께 변화에 따른 트랜스듀서의 특성 변화를 계산한 결과들에 대해 회귀분석을 실시하였다. 일반 적으로 사용되는 세 개의 변수를 가지는 2 차 회귀모 형은 식(1)과 같다. ${ }^{[13]}$

$$
\begin{aligned}
y= & a_{1} x_{1}^{2}+a_{2} x_{2}^{2}+a_{3} x_{3}^{2}+b_{1} x_{1}+b_{2} x_{2}+b_{3} x_{3} \\
& +c_{1} x_{1} x_{2}+c_{2} x_{1} x_{3}+c_{3} x_{2} x_{3}+d
\end{aligned}
$$

여기서 $a_{1}, a_{2}, a_{3}, b_{1}, b_{2}, b_{3}, c_{1}, c_{2}, c_{3}, d$ 는 회귀계수이 고, $x_{1}, x_{2}, x_{3}$ 는 설계변수이다. 식(1)을 이용하여 회 귀방정식을 도출하면, 변수의 최고차항 $\left(x_{1}^{2}, x_{2}^{2}, x_{3}^{2}\right)$ 의 계수는 항상 단일계수 $\left(a_{1}, a_{2}, a_{3}\right)$ 로 정해지게 된 다. 이는 식(1)에서는 변수 $x_{1}, x_{2}, x_{3}$ 의 수치가 바뀌 더라도 함수의 경향은 아래로 볼록하거나 위로 볼록 한 경우 중 하나만 표현이 가능하다. 수집된 수치가 변수의 변화에 따라 다양한 경향이 나타난다면 식(1) 을 이용하여서는 적절한 회귀분석이 어렵다. 따라서 본 연구에서는 변수의 최고차항의 계수를 단일계수 가 아닌 여러 계수의 합으로 표현하기 위해서 회귀 모형을 식(2)와같이 변형하였다. $a_{1}, a_{2}, a_{3}, b_{1}, b_{2}, b_{3}$, $c_{1}, c_{2}, c_{3}, d, e_{1}, f_{1}, f_{2}, f_{3}, g_{1}, g_{2}, g_{3}, h, j_{1}, j_{2}, j_{3}, k_{1}, k_{2}$, $k_{3}, k_{4}, k_{5}, k_{6}$ 는 회귀계수이다.

$$
\begin{aligned}
& y=a_{1} x_{1}^{2}+a_{2} x_{2}^{2}+a_{3} x_{3}^{2}+b_{1} x_{1}+b_{2} x_{2}+b_{3} x_{3} \\
& +c_{1} x_{1} x_{2}+c_{2} x_{1} x_{3}+c_{3} x_{2} x_{3}+d+e_{1} x_{1}^{2} x_{2}^{2} x_{3}^{2} \\
& +f_{1} x_{1}^{2} x_{2}^{2} x_{3}+f_{2} x_{1}^{2} x_{2} x_{3}^{2}+f_{3} x_{1} x_{2}^{2} x_{3}^{2}+g_{1} x_{1}^{2} x_{2} x_{3} \\
& +g_{2} x_{1} x_{2}^{2} x_{3}+g_{3} x_{1} x_{2} x_{3}^{2}+h x_{1} x_{2} x_{3}+j_{1} x_{1}^{2} x_{2}^{2} \\
& +j_{2} x_{1}^{2} x_{3}^{2}+j_{3} x_{2}^{2} x_{3}^{2}+k_{1} x_{1}^{2} x_{2}+k_{2} x_{1}^{2} x_{3}+k
\end{aligned}
$$

변형된 회귀모형에서 변수 $x_{2}$ 와 $x_{3}$ 를 1 로 가정하 면, $x_{1}^{2}$ 의 계수는 단일계수가 아닌 계수들의 합 $\left(a_{1}+e_{1}+f_{1}+f_{2}+g_{1}+j_{1}+j_{2}+k_{1}+k_{2}\right)$ 으로 표현된 다. 따라서 식(2)는 수집된 수치의 다양한 경향이 표 현 가능하므로, 식(2)를 이용하여 회귀분석을 진행하 였다. 목적함수로 사용하기 위한 $\triangle f$ 와 제한함수로 사용하기위한 $f_{c}, f_{1}$ 을 식(3) (5)와같이 도출하였다.

$$
\begin{aligned}
\Delta f= & -1472.1 x_{1}^{2}-928.5 x_{2}^{2}-527.9 x_{3}^{2} \\
& +1961.8 x_{1}-111.6 x_{2}+984.2 x_{3} \\
& -276.8 x_{1} x_{2}+1423.5 x_{1} x_{3}-446.4 x_{2} x_{3} \\
& +31169.4+3128.4 x_{1}^{2} x_{2}^{2} x_{3}^{2} \\
& +1179.1 x_{1}^{2} x_{2}^{2} x_{3}+277.3 x_{1}^{2} x_{2} x_{3}^{2} \\
& -4128.1 x_{1} x_{2}^{2} x_{3}^{2}+395.7 x_{1}^{2} x_{2} x_{3} \\
& -932.0 x_{1} x_{2}^{2} x_{3}-326.7 x_{1} x_{2} x_{3}^{2} \\
& -61.6 x_{1} x_{2} x_{3}-2340.6 x_{1}^{2} x_{2}^{2}+0.0 x_{1}^{2} x_{3}^{2} \\
& +0.0 x_{2}^{2} x_{3}^{2}+0.0 x_{1}^{2} x_{2}-2006.6 x_{1}^{2} x_{3} \\
& +0.0 x_{2}^{2} x_{1}+0.0 x_{2}^{2} x_{3}+4015.8 x_{3}^{2} x_{1} \\
& +384.1 x_{3}^{2} x_{2}
\end{aligned}
$$

$$
\begin{aligned}
f_{c}= & -671.5 x_{1}^{2}-351.8 x_{2}^{2}-287.0 x_{3}^{2}+885.8 x_{1} \\
& -217.2 x_{2}+463.8 x_{3}-50.5 x_{1} x_{2} \\
& +688.4 x_{1} x_{3}-228.5 x_{2} x_{3}+26897.1 \\
& +1691.8 x_{1}^{2} x_{2}^{2} x_{3}^{2}+637.7 x_{1}^{2} x_{2}^{2} x_{3}+65.0 x_{1}^{2} x_{2} x_{3}^{2} \\
& -1871.6 x_{1} x_{2}^{2} x_{3}^{2}+205.8 x_{1}^{2} x_{2} x_{3}-461.5 x_{1} x_{2}^{2} x_{3} \\
& -146.2 x_{1} x_{2} x_{3}^{2}-16.6 x_{1} x_{2} x_{3}-1330.6 x_{1}^{2} x_{2}^{2} \\
& +0.0 x_{1}^{2} x_{3}^{2}+0.0 x_{2}^{2} x_{3}^{2}+0.0 x_{1}^{2} x_{2}-1046.6 x_{1}^{2} x_{3} \\
& +0.0 x_{2}^{2} x_{1}+0.0 x_{2}^{2} x_{3} \\
& +1768.7 x_{3}^{2} x_{1}+240.5 x_{3}^{2} x_{2} \\
&
\end{aligned}
$$

$$
\begin{aligned}
f_{1} & =64.5 x_{1}^{2}+112.7 x_{2}^{2}-22.6 x_{3}^{2}-94.8 x_{1} \\
& -161.2 x_{2}-28.4 x_{3}+88.3 x_{1} x_{2}-22.4 x_{1} x_{3} \\
& -5.6 x_{2} x_{3}+11312.2+130.8 x_{1}^{2} x_{2}^{2} x_{3}^{2} \\
& +45.9 x_{1}^{2} x_{2}^{2} x_{3}-73.3 x_{1}^{2} x_{2} x_{3}^{2}+192.6 x_{1} x_{2}^{2} x_{3}^{2} \\
& +8.5 x_{1}^{2} x_{2} x_{3}+3.5 x_{1} x_{2}^{2} x_{3}+16.8 x_{1} x_{2} x_{3}^{2} \\
& +14.2 x_{1} x_{2} x_{3}-164.2 x_{1}^{2} x_{2}^{2}+0.0 x_{1}^{2} x_{3}^{2} \\
& +0.0 x_{2}^{2} x_{3}^{2}+0.0 x_{1}^{2} x_{2}-40.9 x_{1}^{2} x_{3}+0.0 x_{2}^{2} x_{1} \\
& +0.0 x_{2}^{2} x_{3}-240.0 x_{3}^{2} x_{1}+48.1 x_{3}^{2} x_{2} .
\end{aligned}
$$




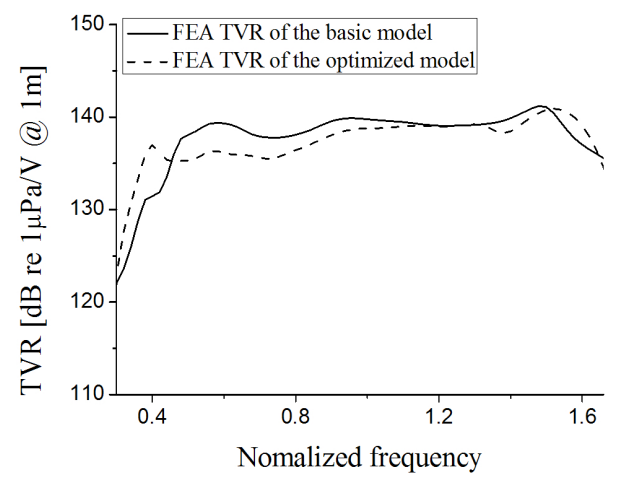

Fig. 8. Comparison of TVR spectra of the basic and optimized models.

도출된 회귀방정식을 이용하여 식(6)과 같이 목적 함수로는 $\triangle f$ 가 최대가 되고, 제한조건으로는 정규 화된 중심주파수 $f_{c}$ 가 0.9 이상 1.1 이하, 대역폭내 하 한주파수 $f_{1}$ 이 0.6 이하가 되는 조건을 설정하였다. 최적화는 유전자 알고리즘을 사용하였으며, ${ }^{[12]}$ 최적 화 결과로 전면추의 두께 $23.6 \mathrm{~mm}$, 전면추 상판의 두 께 $5.3 \mathrm{~mm}$, 후면추의 두께 $17.5 \mathrm{~mm}$ 인 경우 제한조건 을 만족하며 목적함수가 최대가 되었다. 최적화가 이루어진 모델과 기본 모델의 TVR스펙트럼을 Fig. 8 에 나타내었다. 기본 모델의 $-6 \mathrm{~dB}$ 비대역폭이 $115.9 \%$ 였던 것에 비해 최적모델의 $-6 \mathrm{~dB}$ 비대역폭이 $130.6 \%$ 로 약 $15 \%$ 정도 증가하여, 회귀분석과 유전자알고 리즘을 이용한 최적구조설계가 제대로 이루어진 것 을 확인할 수 있다.

$$
\text { Target function: }\left\{\begin{array}{l}
\text { Maximize } \Delta f\left(x_{1}, x_{2}, x_{3}\right) \\
\text { Subject to } f_{1} \leq 0.6,0.9 \leq f_{c} \leq 1.1
\end{array}\right. \text {. }
$$

\section{4. 중공형 Tonpilz 트랜스듀서의 제작 및 특성 측정}

설계 결과에 대한 검증을 위하여 3절에서 도출된 치수대로 중공형 Tonpilz 트랜스듀서를 제작하였다. 해석에 사용된 재료와 동일한 재료를 이용하여 트랜 스듀서를 제작하였다. 중공형 전면추를 사용하기 때 문에 제작의 용이성을 위하여 전면추는 Fig. 9(a)와 같이 상판과 기둥으로 이루어진 부품과, 덮개와 하 판으로 이루어진 부품의 조립형으로 제작되었다. 제
작된 중공형 Tonpilz 트랜스듀서는 Fig. 9(b) 와 같다.

제작된 중공형 Tonpilz 트랜스듀서의 공기중 임피 던스를 임피던스 분석기(Agilent 4294A)를 이용하여 측정하여, 유한요소 모델로 해석한 임피던스 스펙트 럼과 비교하여 Fig. 10에 나타내었다. 주파수에 따른 전체적인 임피던스 스펙트럼이 매우 비슷한 것으로 나타났으며, 이로서 제작된 트랜스듀서 시제품이 설 계된 구조 및 물성을 잘 반영하고 있다고 할 수 있다.

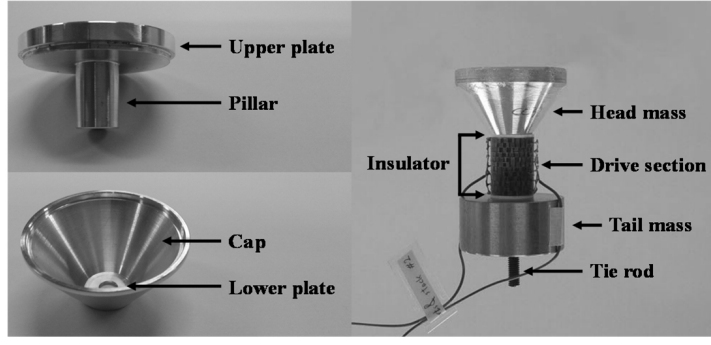

(a)

(b)

Fig. 9. Prototype of the cavity-type Tonpilz transducer: (a) Components of the head mass, (b) Cavity-type Tonpilz transducer.

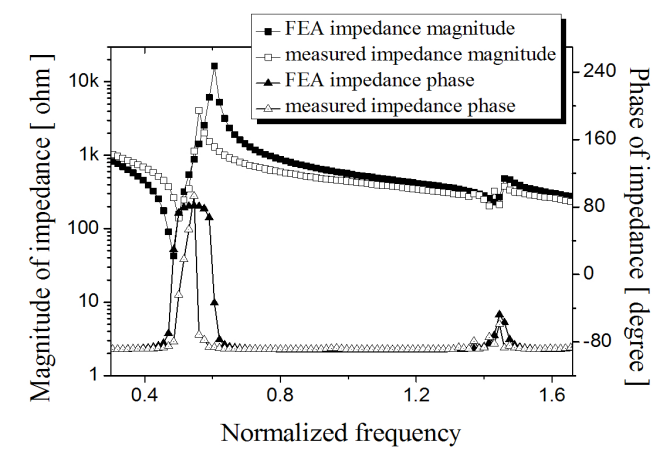

Fig. 10. Comparison of the measured and calculated impedance spectra in air.

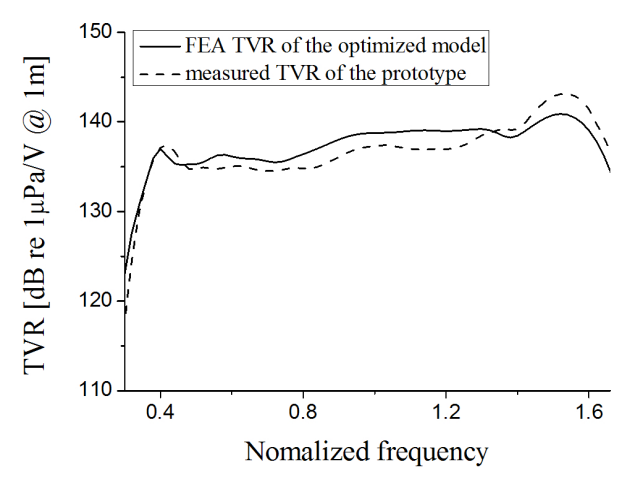

Fig. 11. Comparison of the calculated and measured TVR spectra in water. 
단, 해석결과와측정결과에서 공진과 반공진 주파수 값에서 약간의 차이가 있는데, 이는 시제품의 제작 공차로 인한 것으로 판단된다.

다음으로 제작된 시제품의 수중 송신특성인 TVR 스펙트럼을 실험적으로 측정하여, Fig. 11에 해석결 과와 비교하였다. $-6 \mathrm{~dB}$ 대역폭 구간에서 두 스펙트 럼이 전반적으로 잘 일치하는 것을 확인할 수 있다. 통과대역 구간에 보이는 어느 정도의 차이는 Fig. 10 에서 확인된 트랜스듀서 제작상의 공차와 더불어 TVR 측정상의 오차에 의한 것으로 판단된다. Fig. 11 에 보인측정 결과에서의 $-6 \mathrm{~dB}$ 비대역폭 $\triangle f$ 는 $131 \%$ 인 것으로 나타났다. 통상의 단일모드형 Tonpilz 트 랜스듀서의 비대역폭이 $10 \%$ 20\%임을 감안하면 이는 매우 넓은 값이며, 따라서 본 연구에서 제시한 중공형 Tonpilz 트랜스듀서가 광대역 주파수 특성을 잘 구현할 수 있음을 입증하는 결과이다.

\section{5. 결 론}

본 연구에서는 광대역 Tonpilz 트랜스듀서를 구현 하기 위해 중공형 전면추 구조를 가지는 트랜스듀서 를 선정하였다. 종방향 모드와 flapping 모드를 이용 한 다중모드를 효율적으로 구현하기 위해 유한 요소 해석을 통해 최적 구조를 설계하였다. 설계된 구조 의 타당성과 중공형 전면추 구조의 효과를 검증하기 위해 설계된 구조대로 시제품을 제작하고, 그 성능 을 실험적으로 측정하여 해석 결과와 비교하였다. 제작된 중공형 Tonpilz 트랜스듀서의 임피던스 및 $\mathrm{TVR}$ 스펙트럼 측정결과는 전반적으로 해석결과와 잘 일치하였으며, $-6 \mathrm{~dB}$ 비대역폭 $\triangle f$ 는 $131 \%$ 인 것 으로 확인되었다. 이는 일반적인 Tonpilz 트랜스듀서 의 비대역폭 $10 \% \sim 20 \%$ 에 비하면 매우 넓은 값으로 써, 본 연구에서 제안한 중공형 트랜스듀서는 목표 로 한 광대역 특성을 잘 구현할 수 있음을 입증한 것 이다. 본 연구에서 개발된 광대역 중공형 Tonpilz 트 랜스듀서는 보다 정확한수중통신 및 탐지에 유용하 게 활용될 수 있을 것으로 기대된다.

\section{감사의 글}

본 연구는 국본 연구는 방위사업청과 국방과학연 구소의 지원으로 수행되었습니다(계약번호UD130007 DD).

\section{References}

1. Q. Yao and L. Bjørnø, "Broadband Tonpilz underwater acoustic transducers based on multimode optimization," IEEE Trans. Ultrason. Ferroelect. Freq. Contr. 44, 1060-1066(1997).

2. W. S. Burdic, Underwater Acoustic System Analysis, (Prentice Hall, Englewood Cliffs, 1991), pp. 1-15.

3. K. Zhang, D. Wang, P. Wang, and Y. Du, "Research on the broadband dual-excited underwater acoustic transducer," Advanced Engineering Forum, 2-3, 144-147 (2012).

4. R. F. W. Coates, "The design of transducers and arrays for underwater data transmission," IEEE J. Oceanic Eng. 16, 123-135 (1991).

5. J. L. Butler and A. L. Butler, U. S. Patent No. 8,072,843 Stepped Multiply Resonant Wideband Transducer Apparatus, 2011.

6. G. C. Rodrigo, Analysis and design of piezoelectric sonar transducers (Ph. D. Thesis, London, 1970).

7. S. C. Butler, "Triply resonant broadband transducers," Oceans '02 MTS/IEEE 4, 2334-2341 (2002).

8. J. Kim, H. Kim, and Y. Roh, "Design and fabrication of multi-mode wideband Tonpilz transducers" (in Korea), J. Acoust. Soc. Kr. 32, 191-198 (2013).

9. J. L. Butler, J. R. Cipolla, and W. D. Brown, "Radiating head flexure and its effect on transducer performance," J. Acoust. Soc. Am. 70, 500-503 (1981).

10. S. Chhith and Y. Roh, "Wideband Tonpilz transducer with a cavity inside a head mass," Jpn. J. Appl. Phy. 49, 07HG08-1-07HG08-5 (2010).

11. J. Kim, S. Pyo, and Y. Roh, "Derivation of single phase material properties equivalent to 1-3 piezoelectric composites by the resonant method" (in Korea), J. Acoust. Soc. Kr. 30, 368-376 (2011).

12. Y. R. Roh and X. Lu, "Design of an underwater Tonpilz transducer with 2-2 mode piezocomposite materials," J. Acoust. Soc. Am. 119, 3734-3740 (2006).

13. S. H. Park, Design of Experiments (Minyoung Publishing Co., Seoul, 2012), pp. 255-278. 


\section{저자 약력}

- 김 현 기 (Hyunki Kim)

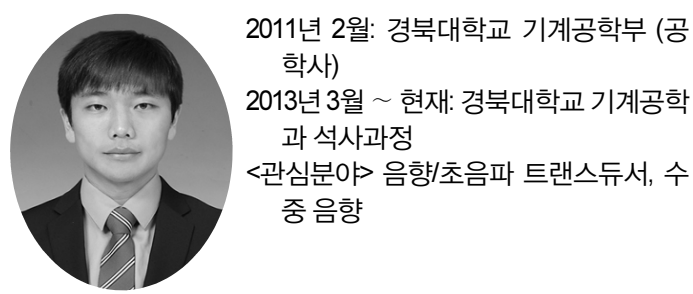

- 임 영 섭(Youngsub Lim)

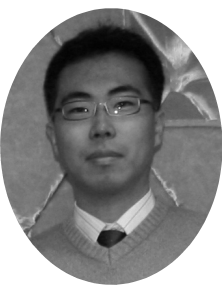

2007년 2월: 대구대학교 정보통신공학부 (공학사)

2009년 2월: 경북대학교 센서 및 디스플레 이공학과 (공학석사)

2009년 3월 현재: 경북대학교 센서 및 디 스플레이공학과 박사 과정

<관심분야> 수중 음향, 초음파 및 탄성파

- 노 용 래 (Yongrae Roh)

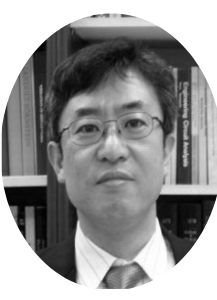

1984년 2월: 서울대학교 자원공학과 (공 학사)

1986년 2월: 서울대학교 자원공학과 (공 학석사)

1990년 5월: 미국 펜실베니아주립대학교 (공학박사)

1990년 5월 1994년 2월: 포항산업과학 연구원 선임연구원

1994년 3월 현재: 경북대학교 기계공학 부 교수

<관심분야> 음향/초음파 트랜스듀서, 압 전 Device, 전자재료, 파동해석 